\title{
Closing information gaps in Kakuma Refugee Camp: A youth participatory action research study
}

Running head/ short title: Closing information gaps in Kakuma Refugee Camp

Michelle J. Bellino and the Kakuma Youth Research Group

\section{Abstract:}

This study explores the role of academic and social support on young people's educational pursuits in Kenya's Kakuma Refugee Camp. Pairing ethnographic methods with youth participatory action research, we find that support often manifests as abstract, decontextualized encouragement with little grounding in the educational opportunity structure. We argue that this motivational discourse generates information gaps, fueling aspirations that neither prepare youth for understanding, nor navigating the constraints they will encounter. In response, we designed a social media platform orienting Kakuma youth to the opportunity structure, while encouraging them to set realistic goals and plan accordingly. Designing a resource by, for, and with Kakuma youth, we illustrate that refugees have the rights and means to access information on which their everyday wellbeing and futures depend. This study illustrates that critical understanding of local and global opportunities can empower, rather than demoralize, young people as they shape their futures in exile.

Keywords: refugee, displacement, youth agency, education, youth participatory action research, aspiration

\section{Corresponding Author:}

Michelle J. Bellino,

School of Education, University of Michigan

610 E. University Ave, Ann Arbor, MI 48109

E-mail: bellino@umich.edu

This is the author manuscript accepted for publication and has undergone full peer review but has not been through the copyediting, typesetting, pagination and proofreading process, which may lead to differences between this version and the Version of Record. Please cite this article as doi: 10.1002/ajcp.12277 
Kakuma Youth Research Group,

https://www.facebook.com/Kakuma-Youth-Opportunities-for-Lifelong-Learning$233327623738937 /$

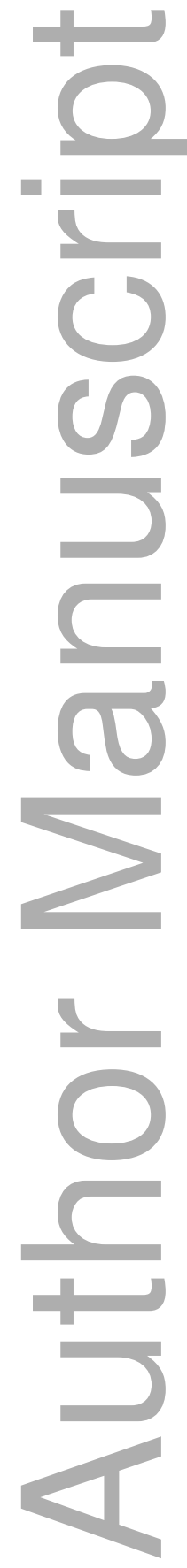

This article is protected by copyright. All rights reserved 


\section{Received Date:}

Revised Date:

Accepted Date:

\section{Article Type: Original Article \\ Closing information gaps in Kakuma Refugee Camp: A youth participatory action research study}

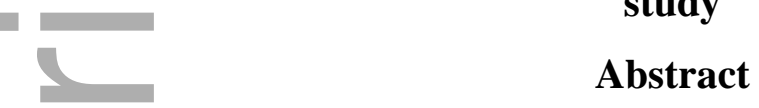

This study explores the role of academic and social support on young people's educational pursuits in Kenya's Kakuma Refugee Camp. Pairing ethnographic methods with youth participatory action research, we find that support often manifests as abstract, decontextualized encouragement with little grounding in the educational opportunity structure. We argue that this motivational discourse generates information gaps, fueling aspirations that neither prepare youth for understanding, nor navigating the constraints they will encounter. In response, we designed a social media platform orienting Kakuma youth to the opportunity structure, while encouraging them to set realistic goals and plan accordingly. Designing a resource by, for, and with Kakuma youth, we illustrate that refugees have the rights and means to access information on which their everyday wellbeing and futures depend. This study illustrates that critical understanding of local and global opportunities can empower, rather than demoralize, young people as they shape their futures in exile.

In conflict-affected settings, access to school has been regarded as an inherently restorative and normalizing aspect of childhood, aimed at protecting young people from harm and orienting them toward the promise of a better future - optimally, one shaped through educational attainment. However, the structural rigidity and perpetual waiting characteristic of settings of encampment destabilizes the social purpose and relevance of school, as well as one's sense of agency to shape a better future through the pursuit of formal education. Even when young people set high aspirations and develop a strong sense of efficacy as learners, they may (rightly) perceive little control over the social and political forces that shape their educational trajectories in exile. Given these constraints, how do young people in these settings remain hopeful about their educational aspirations? Emphasizing the expertise of those who directly experience contexts that researchers and policymakers seek to understand and - often - to change, this study offers unique insight into 
refugee youth conceptions of educational programming that is relevant to their current needs and future aspirations.

This paper draws on a three-year study spanning 2015-2017, exploring educational experiences and aspirations among youth completing secondary school in Kakuma Refugee Camp in Kenya. Pairing ethnographic methods with a youth participatory action research (YPAR) collaboration, we set out to understand how academic and social supports influence youth motivation toward secondary and post-secondary educational pursuits. We found that manifestations of support often take the form of abstract, decontextualized encouragement with little grounding in the opportunity structure within the camp setting. We argue that advice and encouragement to continue one's education have limited value when decontextualized from the restrictive and competitive nature of the existing opportunity structure. Rather than empower youth to actively plan their futures, these modes of support fuel short-term hopes and expectations that risk setting youth up for long-term disappointment. Moreover, the nature of education in a severely under-resourced context has enforced a culture of individual and identity-based competition, hindering supportive exchanges outside close-knit identity groups. Consequently, non-material supports are not equitably distributed, often accrued within distinct social networks. In response to these findings, we designed a social media platform intended to explicitly link advice and encouragement to existing opportunities available to Kakuma youth.

Through the process of compiling and circulating information, we challenged dominant assumptions about refugee youth passivity, dependency, and overall powerlessness to shape the course of their lives (also see Dryden-Peterson, 2011). Asserting our "right to research" (Appadurai, 2006), we demonstrate the essential role that transparency and access to reliable information plays in self-advocacy for marginalized populations, particularly when combined with other elements of support. Designing a shared resource by, for, and with Kakuma youth, we illustrate that young people — even those lacking legal citizenship status - have the rights and means to access information on which their everyday wellbeing and future livelihoods depend. This study contributes to our understanding of empowerment processes amongst refugee youth enduring conditions of "static transience" (Oka, 2014, p. 24), an under-theorized domain within empowerment studies and a population rarely given voice in academic texts. Our findings suggest that transparency and reliability, both in terms of access to services and understandings of one's rights and entitlements to these services, lead to a greater sense of control and agency. 
Understanding educational (dis)continuities enables youth to identify and navigate the structural barriers they encounter while shaping their educational pursuits in exile.

In the following sections, we describe the research context and methods undertaken in this collaborative study. We then discuss the role of non-material, relational support in a context where secondary school access, completion, and academic performance are among the lowest rates globally (Dryden-Peterson, 2016; UNHCR, 2016a). Drawing on a variety of data sources, including interviews carried out by youth co-researchers, ethnographic observations collectively analyzed, and firsthand experiences as Kakuma youth, we illustrate the presence of information gaps, wherein young people routinely shape future aspirations with little understanding of the opportunities available to them. We analyze these findings through the lens of critical hope, recognizing the need to both support young people's understandings of sociopolitical systems and global power inequities, along with their sense of civic agency to participate in, and transform, these structures. Throughout, we explore underlying conceptions of agency amongst youth who lack legal citizenship status and are subject to the flux characteristic of displacement settings, finding that abstract hope often displaces efforts to strategically plan for the future. We close with implications for educational and youth programming. ${ }^{1}$

\section{Research Context}

Kenya hosts one of the largest refugee populations in the world. Kakuma Refugee Camp, established in 1992, is currently home to 176,872 refugees, 87,098 of which are school-aged children and youth. The United Nations High Commission for Refugees (UNHCR) manages the provision of education within the camp and has recently expanded post-primary educational opportunities. Even as UNHCR works to increase the availability of secondary schools, the social demand for post-primary education remains low relative to the camp population: more than half of school-age youth in Kakuma do not attend secondary school. In part, this is the result of a structural gap between the number of primary and secondary institutions in the camp (See Figure 1). As camp institutions have become overstretched, access and persistence in upper grades are hindered based on perceptions of poor learning conditions and low quality education. There is also an emergent critique of the limited utility and value of secondary education in a setting with legal restrictions on

\footnotetext{
${ }^{1}$ This paper is co-authored by youth co-researchers. In the interest of transparency, we use the first person singular to signal decisions made by the adult facilitator, while first person plural represents the perspective of youth involved in the YPAR collaboration. We further distinguish between youth as co-researchers and our interview participants, as the experiences of both constitute sources of data relevant to this study. These representational decisions are discussed in the methods section.
} 
the right to work and few opportunities to access tertiary education.

\section{[Insert Figure 1]}

Set within an educational policy of national integration, camp schools implement the Kenyan curriculum and adhere to Ministry of Education structures and guidelines. Kenya's educational system is steeped in a competitive, high-stakes exam culture, with performance on the Kenya Certificate of Primary Education (KCPE) determining one's possibilities for accessing secondary education. Likewise, performance on the Kenya Certificate of Secondary Education (KCSE) restricts college and university access to the highest performing students. As education has become prioritized within humanitarian and development interventions, a number of organizations have created post-secondary scholarships to support individual refugees. College and university pursuits are routinely upheld as the idealized post-secondary pathway and a singular opportunity for socioeconomic and spatial mobility (AUTHOR 1). Cultural scripts of meritocracy shape everyday practices in camp schools, yet these opportunities are rarely contextualized in terms of local, national, or global trends. Globally, less than $1 \%$ of refugees are able to access post-secondary education (UNHCR, 2016a).

In the context of escalating global migration, the average duration of exile now spans more than two decades (UNHCR, 2015). With displacement increasingly protracted, formal education cannot solely prepare students for eventual repatriation (Dryden-Peterson, 2016). As the numbers of "schooled" and "unschooled" Kakuma youth rise, UNHCR is actively searching for programming solutions that foster integration and livelihood opportunities for youth in their host country of Kenya. This youth collaboration was conceptualized as an opportunity to explore how Kakuma youth understand and experience the educational opportunities available to them, as well as how they shape their future aspirations in relation to educational attainment in exile. YPAR is vital to our understanding of the experiences of those most marginalized within educational structures (Cammarota and Fine 2008; Ginwright, Cammarota and Noguera 2006). Although research and community interventions aimed at youth participation have proliferated in recent years, collaborations rarely extend to refugee youth, even in contexts of resettlement where young people's legal status is less tenuous (e.g., Couch \& Francis, 2006). The experiences of young people are particularly marginalized in settings of encampment, where even adults access few spaces to exercise their political voice.

\section{Research Design and Methods}




\section{Ethnographic and Youth Participatory Action Approaches: An Evolving Collaborative}

\section{Inquiry}

Data collection spanned three years (2015-2017), with approximately two months of focused, field-based research per year. This multi-year approach was designed to trace the experiences of a youth cohort transitioning from Form $3\left(11^{\text {th }}\right.$ grade $)$ to Form $4\left(12^{\text {th }}\right.$ grade $)$, and the year following school completion. During the first two years, I (the adult facilitator) carried out participant observation throughout the school day, attending formal and informal school events. In the final year, I visited youth in their homes, communities, university classrooms, or workplaces. In tandem with these approaches, I initiated meetings with fourteen interested students to discuss their educational experiences and future aspirations, while identifying and critically analyzing the supports, resources, and challenges in their lives that interacted with their educational trajectories. These sessions were grounded in a Youth Participatory Action Research (YPAR) approach, in that youth were positioned as co-researchers with the agency to shape the research process and collectively identify actions through which to make change in their school and community (Cammarota \& Fine, 2008; Rodriguez \& Brown, 2009). In addition to teaching research skills, meetings aimed to foster dialogue about the shared challenges of Kakuma youth and to support students in designing an inquiry relevant to youth concerns and priorities. Collectively, we identified the research questions that animate this study, as well as the methodological decisions and protocols.

The YPAR collaboration can be conceived as nesting within an ethnographic documentation of Kakuma's educational landscape and youth's postsecondary transitions. In designing this study, I drew on recent works (Dyrness 2011, Guishard 2009, Nygreen, 2013) that have combined ethnography and participatory action research, leading to empirical and theoretical insights, transformative openings, and opportunities to reflect constructively on research collaborations. This study shares these aims in understanding how a specific sample of marginalized individuals is able to draw on research methods to enact their "right to research" (Appadurai 2006), using data to document their challenges and inform their vision of relevant and socially just educational opportunities. This paper draws primarily on interview data collected by youth and reflections drawn from our collaborative process, further described below. Ethnographic and YPAR approaches can work toward partnerships that move beyond "projects" into sustainable efforts authored and maintained from within communities (Kidd, Davidson, Frederick, \& Kral, 2017; Langhout \& Thomas, 2010; Ozer, Ritterman, \& Wanis, 2010; Schensul, Berg, \& Sydlo, 2004). This 
study was intentionally designed to be multilayered, facilitating YPAR as an opportunity to mobilize youth participation during multiple stages of the research process, while employing ethnographic methods to document the YPAR process over time.

The nature and frequency of YPAR meetings varied, given the unpredictable nature of camp schools and life in the camp more generally. School closures and impromptu schedule changes due to special events, frequent illness and absences of both students and teachers, and environmental barriers such as flooding made a regular schedule impossible. We aimed to meet three times per week, ranging from 20-minute check-ins to multi-hour sessions. Given the distance between students' homes and restrictions on movement within the camp, we either met on school grounds or in a structure reserved for educational purposes. We met during canceled classes and breaks during the school day, in addition to occasional weekends. After students graduated, we organized our meetings around members' work, family, and community obligations and were able to meet more regularly. Our meetings largely took place in a small, empty classroom with dirt floors and gaping holes in the concrete walls, worn down from seasonal flooding. Camp schools are under-resourced and overcrowded. Finding unoccupied spaces was a challenge, often leaving us with the least desirable rooms. In stark contrast to the rows of desks and benches in their classrooms, we arranged our chairs in a circle. This formation was difficult with limited, often broken furniture. It was also a challenge to students' styles of learning and interacting with one another, in that it emphasized dialogue and egalitarianism rather than rote content and rigid hierarchies. Group decisions were made through dialogue and debate. When we could not reach consensus, we discussed how to move forward. For example, as we contemplated options for disseminating our research findings, Mustafa posed this question to the research team: "Should we vote, or should we discuss and [then] vote? ... I think we should discuss... we can hear all the ideas before we vote... then know more what we are voting [on],"

Early in our YPAR conversations, we distinguished between material, institutional, and nonmaterial support. In making these distinctions, we recognized that we had greater control, and were in a stronger position to affect change, over the realm of non-material, relational support. As Clinton reflected, "We already know... what will happen if we have more schools, teachers, books. What we do not know is about this non-material support." We settled on an initial exploratory research question: What is the role of non-material support in the educational experiences of students and out of school youth in Kakuma? We wrote this question in the front of our research notebooks in big letters, returning to these words often. At the time, non-material support largely 
referred to academic support. It also encompassed the ways that families and communities positioned formal education in the camp and the extent to which they actively encouraged young people's ambitions to attend and complete school. As a result of this study, our conceptions of the nature and distribution of non-material support shifted, and our research collaboration became more focused on the role of informational exchanges as a vital form of support that was not easily or equitably accessed.

\section{Inviting Youth Co-Researchers}

The composition of the research team was, in part, determined by the interest of a teacher volunteer, who facilitated communication amongst group members between field visits and school breaks. This teacher's involvement narrowed recruitment to a single class within the Form 3 cohort, in order to align classroom-based observations with youth involvement in the research collaboration. The rationale was that, over time, I would observe youth cultivating a range of educational aspirations in the context of everyday challenges they confronted within and outside the classroom. In addition to triangulating data, this alignment allowed for pedagogical benefits such as building links between curriculum, class interactions, and issues discussed in the context of our research meetings.

Managing students' perceptions of fairness and equity was vital to the process of selecting youth co-researchers. Within the focal class, I invited twenty students from diverse backgrounds, aiming for variation in gender, nationality, time in exile, and academic performance. Emphasizing these individuals' right to decline participation was key to ensuring a group of co-researchers with vested interest in the collaboration and with a keen awareness of research ethics as they embarked on their own data collection. By the third week, we had established a team of fourteen members. ${ }^{2}$ Despite efforts to include a diverse population in the collaboration, co-researchers were largely male youth representing several countries of origin. Though Kakuma hosts upwards of fifteen nationalities, the largest youth populations are Sudanese, South Sudanese, and Somali. Female students enroll in secondary school at lower rates than males, and they are more likely to drop out in higher grades. These wider trends are reflected within the composition of our research group.

\section{Data Collection}

\footnotetext{
2 Over time, participation in the YPAR collaboration fluctuated. In total 17 members rotated in and out of the group, in addition to one (male) teacher (12 male, 6 female; 2 Kenyan, 1 Kenyan-Ugandan, 4 Sudanese, 6 South Sudanese, 4 Somalis, and 1 Congolese). Though we maintained contact with those who no longer participated, by 2017 our team had 7 active members in Kakuma, in addition to the teacher (6 male, 2 female; 1 Kenyan, 2 Sudanese, 4 South Sudanese, 1 Somali).
} 
Youth co-researchers interviewed 32 members of the Kakuma community, ranging in gender, age, country of origin, time in exile, and educational credentials. (See Table 1 for participant demographics.) We designed a shared interview protocol inquiring about participants' experiences with schools in Kakuma, their short and long-term aspirations in relation to educational pursuits, and the nature of academic and social supports in their lives. Youth researchers carried out interviews individually or in pairs, audio recording when possible. In many cases, interviewers chose to interview relatives, friends, or family members of the same gender and tribe, thus amplifying some of the over-representation of select identity groups already present on our team. Despite that interviews often took place within existing social networks, co-researchers reported learning details about participants' experience with conflict, displacement, or education that were previously unknown. Following interviews, we created profiles for each participant (Seidman, 2013, pp. 121-127). Interview profiles served as a form of immediate reflection and helped us track various participants by listing main themes that surfaced during the interview. In addition, we wrote memos based on a thinking protocol that asked interviewers to reflect on what was familiar (i.e., confirming data), surprising (i.e., challenging or potentially anomalous data), and memorable (e.g., a striking or pithy quote). In some cases, profiles and memos unearthed emergent analytic themes. These data were recorded in our research notebooks.

\section{[Insert table 1]}

Recognizing that co-researchers were also Kakuma youth with relevant perspectives on the research questions we posed as a team, we sought ways to document our experiences so that they too could be analyzed more systematically. Adut and Clinton came up with the idea of keeping a "diary of support," within our research notebooks where we documented our day-to-day experiences with social and academic supports. These diary entries drew on discussion of ethnographic fieldnotes as a type of data, encouraging students to observe their everyday participation in settings with attention to detail. Some were more invested in their diaries of support than others, such as Mostafa who filled several notebooks over the three years. Recorded YPAR team meetings $(n=46)$ serve as additional sources of data, documenting our collaboration and the evolution of our thinking over time.

\section{Data Analysis}

Analysis was an ongoing, iterative, and collaborative process. As the adult facilitator, I designed pedagogical activities aimed at structuring individual, paired, and group analysis, while 
emphasizing that the substance of the analysis should be driven by youth insights. ${ }^{3}$ Initially, we listened to audio recordings of several interviews and talked at length about coding for emergent themes, while also reflecting on interviewing styles. Subsequently, we drew on written interview transcripts, interview profiles and memos constructed following interviews, and other day-to-day activities in school and the community we had selectively recorded in our research notebooks. Like other researchers working with youth (e.g., Foster-Fishman, Law, Lichty, \& Aoun, 2010), I sought ways to vernacularize coding steps in everyday discourse and through interactive activities.

Co-researchers initially worked individually to generate "open" codes in the margins of the text, then refined codes in pairs, before discussing them with the full group. In line with the democratic principles that guided group decision-making, we analyzed data collaboratively through a process of "collaborative coding" (Smagorinsky, 2008, p. 402), with goals of clarifying, debating, and eventually seeking consensus, rather than inter-rater reliability (Harry, Sturges, \& Klinger, 2005 , p. 6). Whenever possible, individual and paired dialogue preceded collaborative coding in order to encourage a range of views, before narrowing to more "focused" codes. Though we listened to recordings of YPAR meetings, read fieldnotes documenting school interactions, and shared selective entries from diaries of support, most of our collaborative analysis focused on the interviews carried out by youth co-researchers.

Six principal themes emerged as salient across interviews, which informed subsequent analysis and laid the groundwork for the action component of YPAR. Participants attributed their educational successes, challenges, drive, and aspirations to: (1) the availability of university scholarships and access to higher education for refugees, (2) recognition of limited work opportunities in Kakuma requiring educational credentials; (3) nation-building goals and connectedness to one's country of origin, (4) the role of education in their migration story; and the nature, source, and frequency of (5) peer-to-peer and (6) intergenerational support. We further categorized these sources of support as deriving from perceptions of structural (dis)continuity in the camp $(1,2)$; individual and collective aspirations for education shaping a society in transition $(3,4)$, and social and academic supports that circulated through interpersonal and inter-group relationships $(5,6)$. We then explored linkages across these themes, recognizing that young people's varying access, understanding, and experiences with, the educational landscape impacted their aspirations and the supports they could exchange. Patterns such as a lack of material resources, limited social networks, and identity-based discrimination challenged young people's capacity to access and take

\footnotetext{
${ }^{3}$ Given resource constraints, I transcribed and printed interview data so that everyone was able to access the full dataset.
} 
advantage of available supports. Following Charmaz (2006), we recoded data classified as peer-topeer and intergenerational support with an emphasis on active gerunds, foregrounding strategies enacted to support educational pursuits. In refining these (focused) codes, we differentiated between three principal types of relational support: encouraging, advocating, and sharing information. Finally, we carried out a final pass through our interview data, coding specifically for informational exchanges. We elaborate on these themes in the findings section. Independently, the adult facilitator applied this coding scheme to fieldnotes documenting our YPAR meetings. Coded and uncoded excerpts of fieldnotes (documenting school-based observations and YPAR meetings) became shared sources of data that allowed us to intentionally link participants' interview statements to youth coresearchers' reflections.

Analysis of interview data was further informed by co-researchers' experiences with educational discourses and practices in the camp — a unique advantage of PAR, as well as a source of bias (see Kirshner, 2010 pp. 246-247). After completing secondary school and struggling to access opportunities that students had previously believed would be available to them as schoolleavers, youth became more critical of the ways that academic and social support manifested in the camp. Meanwhile, they deepened their understanding of how various forms of support circulated and accumulated within, more often than between, distinct identity groups.

\section{Researcher Positionality, Voice, and Co-Authorship}

As in all youth-oriented research, there are limits on adults' access and participation in young people's social worlds. My (AUTHOR 1) identity as a mzungu (white Westerner) further magnified my status as an outsider in this context. Throughout the research process, I tried to remain cognizant of the power and privilege I carried with me into Kakuma as a white, adult US citizen. In PAR collaborations, power disparities demand particular attention in cases where the facilitator is "an outsider to the community, while also occupying multiple positions of power in relation to other participants" (Nygreen, 2009, p. 19). Under these conditions, Nygreen cautions against facilitating a sense of "false egalitarianism" (p. 18). Similarly, Chataway (1997) suggests that researchers recognize the unlikelihood that extreme power disparities will disappear during the course of collaborative research, instead working to "gain a better understanding of the influence of the existing power by observing its effect on the research collaboration" (p.757). We routinely acknowledged, and made concerted efforts to address, these power inequities within our research collaboration. 
Co-authorship remains a fraught issue in PAR, with most academic texts authored by lead, adult facilitators (Caraballo, Lozenski, \& Lyiscott, 2017). This paper is co-authored, though much of the text has been written primarily by an academic researcher, native English speaker, and the adult facilitator of the YPAR collaboration described here. Recognizing the ways in which "coresearchers' may quickly be transformed into 'research subjects' in the academic texts of a university-based scholar" (Nygreen, 2009, p. 22), this article aims to recognize youth as active shapers of the data collection and analytic process. Importantly, we distinguish between youth as co-researchers (and co-authors of this paper) and participants-largely youth — who shared their experiences with us through the context of our research collaboration. Inspired by Tuck et al. (2008, pp. 62-63), we found productive ways to foreground the plurality of individual identities embedded within our research team through intentional shifts in our narrative voice. Though this is both an inadequate representation of power sharing and makes for inconsistent voice, we assert this as an important reminder of a collaborative process in which substantial power differentials impacted the nature of data collection and analysis.

\section{Framing Dependency, Agency, and Critical Hope}

Schools are envisioned as a primary institution through which young people "figure the future" (Cole \& Durham, 2008), cultivate the "capacity to aspire" (Appadurai, 2004), and develop the knowledge and skills to pursue their imagined futures (Stambach \& Hall, 2017). Looking across children's experiences with conflict, displacement, and schooling in multiple country contexts, Winthrop and Kirk (2008) found that education was linked to young people's wellbeing, but only when students saw themselves engaged in meaningful learning. That is, merely attending school was not enough to help young people "cope and hope" with the lived effects of conflict and displacement (also see Mosselson, Morshed, \& Changamire, 2017). Nevertheless, research carried out in refugee communities demonstrates that sustaining hope continues to be regarded as an essential element of the schooling process for displaced youth (AUTHOR 1; Dryden-Peterson, 2011). Everyday discourses and practices in camp schools are oriented toward renewing young people's optimism and trust in the promise of a better future, more so than pedagogical or curricular goals that might enable them to construct those futures. Related research theorizes that hope projected through education functions as a survival mechanism for young people enduring contexts of uncertainty, risk, and marginalization (Jakimow 2016; Mains 2012). Hope is "an aspect of future making... intertwined with social relationships and institutions" (Cole \& Durham, 2008, p. 16), but many worry that schools too easily manufacture false hope (Duncan-Andrade, 2009; Fine \& Burns, 
2003). Vincent Crapanzano (2003) suggests that hope, in contrast to desire, cannot be fulfilled through one's actions alone. He writes, "hope depends on some other agency - a god, fate, chance, an other-for its fulfillment” (p. 6). King's (2018) findings support the degree of passivity that Kenyan youth inscribe into their visions for the future; she finds young people project individual qualities such as determination and hope, rather than specific actions, as key to realizing their aspirations.

Studies documenting the psychosocial effects of armed conflict and displacement consistently find a loss of agency, self-worth, and a sense of control among those affected by violence and trauma (Davies, 2004; Honwana, 2005; Nordstrom, 2004). Some studies have also linked a diminished sense of agency to post-conflict reconstruction efforts, as interventions have reduced or removed local capacity to make decisions about survivors' lives and contexts (Carballo et al., 2004; Cilliers, 2006; Shaw, Waldorf, \& Hazan, 2010). Constraints on refugee agency are, in part, a consequence of structural arrangements, in that policies of host countries such as encampment result in "enforced dependency" (Harvey \& Lind, 2005, p. 28). Conditions of isolation, exclusion, and the inability to work or otherwise achieve financial autonomy "[prevent] refugees from developing their human potential and [limit] their ability to make a positive contribution to the economy and society of the country which has granted them asylum" (Crisp, 2004, p. 6).

The concept of refugee "dependency syndrome" has been widely critiqued, yet it persists in debates about aid relief and development (Abdi, 2005). Youth across diverse settings of displacement report others" perceptions of them as "lazy... irresponsible, unable to be involved in decision making, inexperienced, and ignorant" (UNHCR, 2016). Meanwhile, policies for displaced young people draw on visions of refugees as "incomplete, uprooted, and traumatized victims" (Epstein, 2010, p. 23). Deficit discourses such as these enforce notions that refugee youth lack both the skill and the will to change the course of their lives, limiting the value of education in exile to protecting and distracting children from harm (Dryden-Peterson, 2011; Winthrop and Kirk, 2008).

Despite impressions that relief aid undermines recipients' self-reliance, services are often too erratically offered to promote a sense of dependency (Harvey \& Lind, 2005). That is, dependency derives from a lack of understanding of how aid is functioning or one's rights within existing structures, whereas agency is linked to dependable services that allow for deliberate, flexible, and strategic planning. We propose a shift in language from concerns over individuals' dependency on organizational services, to a focus on organizations' dependability in offering those 
services and disseminating information to stakeholders about how to access them, "so that those who most need it [aid] understand what they are entitled to, and can rely on it as part of their own efforts to survive” (p. 43). This reframing aligns with Zimmerman's (1990) proposed shift from deficit-oriented studies of "learned helplessness" toward a theory of "learned hopefulness." Distinct from aspiration, this theory of hope is grounded in empowering experiences that facilitate a sense of personal control through the development and practice of "skills that help individuals solve problems, identify resources, and recognize factors that influence decisions" (p. 82).

Recent studies lend further support to the connections between refugee young people's knowledge of services and their capacity for planful action, even when these understandings reveal challenges and scarce opportunities. Comparative research examining refugees' access to higher education finds persistent tensions between inclusivity, transparency, and program capacity (Gladwell, 2016, p. 18). Transparent and accessible selection criteria for educational programming are recognized as a "good practice indicator," helping applicants make informed choices (p. 88). Meanwhile, a recent global consultation with refugee and host community youth representing 34 countries of origin highlights ten principal challenges across diverse contexts of asylum (UNHCR, 2016b). In addition to a lack of educational and employment opportunities, youth consultants identified their struggles to participate in society, including "limit[ed] youth involvement in decision making" and a "lack of relevant, honest, and transparent information about ... refugee rights, [and] available services" (p. 6). Young people shared a sense that their inability to access relevant information or interact directly with organizations that facilitate (and withhold) access to information makes it difficult "to engage constructively with humanitarian actors or make decisions about everyday issues and their futures" (p. 22). In response to these challenges identified by youth, information sharing and networking emerged as one of seven "core actions" from the global consultancy (p. 29), emphasizing the links between information, youth empowerment, and purposeful decision-making.

Recognizing that young people's voice needs to be present in the creation of policy designed to foster their wellbeing, a number of researchers argue for advocacy training so that youth are positioned to defend and claim their rights (e.g., Checkoway \& Richards-Schuster, 2004; Langout \& Thomas, 2010; Prilleltensky, 2010). On a related note, Appadurai (2006) advocates for the "right to research" as essential to everyday civic participation. This right manifests as an entitlement to inquire, measure, document, disseminate, challenge, and act on information, on the basis that “strategic knowledge" and "disciplined inquiries" (p. 167) are critical for informed citizenship or 
for "the pursuit of it [citizenship] for those who are not full citizens" (p. 168). His argument extends beyond the capacity to produce new knowledge. Rather, this right is intimately tied up with the "capacity to aspire" (Appadurai, 2004), in that citizens "need to understand where the best information is available, how much information is enough for a sound decision, where such information is stored, and who might help them to extract what is most significant about it" (Appadurai, 2006, p. 176).

Collaborating with youth co-researchers engendered an opportunity to examine, and ultimately revise, dominant messages that hope alone could fuel educational attainment and grant a better future to individual refugees and their broader communities in exile. In the following sections, we identify vital knowledge and skills Kakuma youth require in order to intentionally draw on existing opportunities to shape their desired futures. In linking abstract hope to the local and global power structures that shape and constrain opportunities in exile, "critical hope" (DuncanAndrade, 2009; also see Christens, Collura, \& Tahir, 2013; Dryden-Peterson \& Reddick, 2017) became construed as usable knowledge, reinforcing youth agency and underscoring the ways in which youths' understandings of their context allowed for intentional educational planning. In this sense, enacting the right to research was both a means and an end to youth participation in this context.

\section{Findings: From data collection to collective action}

\section{Types of Non-Material Support in Kakuma}

Observations and interviews carried out collaboratively demonstrate that young people are embedded in a network of relational interactions pertaining to education. As we observed throughout our schooling, young people regularly advise one another and participate in teaching and learning exchanges with classmates, family, and community members. Initially youth saw themselves solely as recipients of non-material supports, though later came to see themselves as engaged in reciprocal exchanges. Social and academic supports are key to young people's capacity to persevere in camp schools, particularly at the secondary level when concerns about educational utility become more pronounced. Meanwhile, recognition that young people play an active role in distributing non-material support enforced a sense of youth agency while expanding conceptions of support to encompass and validate experiences of "relational empowerment" (Langhout, Collins, \& Ellison, 2014; also see DeJaeghere, Wiger, \& Willemsen, 2016).

Examining participants' (and our own) experiences in Kakuma, we identified three distinct types of non-material support that factored into young people's motivation for pursuing post- 
secondary education. First, we accounted for discourses of encouragement, often expressions of praise for recent accomplishments or optimism in one's potential to perform and advance academically. Across participants, we found this to be the most prominently featured expression of support, and the most widely disseminated across actors. Young people reported teachers, fellow classmates, family and community members, and agency staff who had inspired them with messages of hope. For example, Mary explained, "She [my mother] is always telling me that if I study very hard, I can be taken for further study." Though not all participants expressed feeling personally encouraged, everyone reported exposure to some motivational discourse, often abstract messages encouraging them to work hard in secondary school so that they could receive a scholarship and "be taken" outside the camp for further schooling. The passive positioning of opportunities coming to youth, rather than youth shaping opportunities, reinforced a sense that pursuing further education would be facilitated by outside actors and was not within the control of young people.

Second, we documented instances where friends, family, and community members took action or engaged in advocacy to support young people's education. In some cases, individuals advocated for access to a particular educational resource or opportunity. In other cases, action was aimed at mitigating negative consequences, such as preventing grade repetition or participating in decisions about disciplinary measures for a student's indiscretions. For example, when Rebecca struggled academically, she and her mother considered the option of grade repetition. Instead, Rebecca's mother began plaiting hair in the camp to earn extra income so that she could send Rebecca to a government school, where she would receive more individualized attention. When Ismail's uncle could no longer afford his nephew's school fees in Nairobi, he visited several secondary schools in Kakuma and added his nephew to the waiting list for enrollment. Once he confirmed that enrollment was secure, his uncle sent for Ismail to return to the camp. Both Rebecca and Ismail benefitted from adults who took action to ensure educational access and continuity.

Distinct from encouragement and action, a third type of support emerged, which we termed informational exchanges. These interactions were focused on communicating the availability of existing opportunities, how to access them, and how to construct meaningful, cumulative learning sequences. Informational exchanges proved to be the least prominently featured expression of support noted by participants and co-researchers. In cases where information about concrete opportunities was cited, it was often limited to the availability of higher education scholarships tailored for refugees; however, even these references encompassed limited relevant information 
about eligibility requirements, application procedures, and the highly competitive nature of these opportunities. The YPAR collaboration became a strategic opportunity to document the infrequency of informational exchanges, and an impetus to shape an alternative, more equitable structure for information dissemination.

\section{Decontextualized Hope}

One of the most salient findings gleaned from our interviews was that Kakuma youth, for the most part, shared aspirations to access higher education and gain credentials to attain professional, white-collar employment. Many felt these accomplishments were crucial to successful adulthood and nation-building expectations in exile. (See AUTHOR 1, AUTHOR 2 for further discussion of these findings.) Perceptions of continued educational access and the feasibility of advancing within the current educational opportunity structure are essential determinants in young people's motivation to complete and continue their education (Quinn, 2010). In Kakuma, sustaining this belief requires trust in meritocracy, a sense of individual exceptionality, and, at times, a willful disregarding of the constraints of the opportunity structure. In other words, maintaining hope seemed to necessitate being uncritical. (See Christens, Collura, \& Tahir, 2013 for further discussion of interactions between hope and criticality and their rare co-occurence.) Yet after completing secondary school, youth co-researchers could no longer disregard the scarcity of higher education opportunities. Kariem's brothers did not talk to him for a week when it became clear that he had no college prospects. Ibrahim wondered aloud if school in Kakuma was a waste of time. The collective shame felt during these meetings was palpable. This newfound solidarity between participants and co-researchers stimulated our thinking about how to take collective action in response to our research findings. All students agreed that refrains such as "work hard" and "education is the key to life" were the dominant messages they encountered in school. Concrete advice about how to enact these philosophies, however, proved elusive.

Contrasting the hopeful rhetoric that motivated youth researchers throughout their schooling with the advice they wished they had received led to two insights. First, as high school graduates, young people more realistically accounted for the structural constraints within the camp, recognizing that even the most academically successful youth would face challenges in accessing post-secondary education. Second, advice and encouragement were more useful when accompanied by acknowledgement of the structural constraints, as well as strategies for navigating them. Ethnographic observations supported students' assertions that much of the advice offered to young people was decontextualized from essential information about the nature, timing, and scarcity of 
educational opportunities in the camp. We recalled frequent classroom visits and school assemblies with messages from refugee students whose hard work and sheer will to succeed were rewarded with college scholarships. Turning to [Author 1's] fieldnotes documenting classroom observations in previous years, we were struck by how frequently teachers promoted higher education as the necessary and logical step for all students following secondary school. During a school meeting in their Form 3 year, one teacher encouraged students to excel on the graduation exam so they could be rewarded with a university scholarship abroad. He said, "We want you to go abroad and do your things. With an A, you can get your [scholarship].” In Form 4, months prior to the culminating exam, a teacher visited their classroom urged them to, "Think of your parents... Wherever they are, they are thinking of you and your education. They want you to complete. They want you to move ahead... to go all the way to university."

It was common knowledge that scholarships were competitive; however, the degree of their selectivity in Kenya and globally was not clear. The persistence of meritocratic tropes led some to believe that new programming would be created to accommodate rising numbers of secondary school graduates and a growing interest in postsecondary education. Looking blankly at the walls of his old classroom, Luke explained, "I thought UNHCR will make more scholarships if they see... we want university... [if they see that] everyone wants that chance."

But after completing school, the large majority of youth was left to navigate the uncertainties of post-secondary life without the coveted scholarship they had hoped for, and with little understanding of the alternatives. Youth co-researchers became despondent about their futures and ambivalent about supporting others' educational pursuits, which now seemed to be of limited utility in the camp context. Kariem reflected, "People do keep on saying, please work hard, education is the key to life that can change someone... But then you wonder if you fail, what is next for you?" Some were uncertain how to apply for work in the camp. Others worried that looking for work was a distraction from their real desire to continue education, despite few opportunities for either. We had lengthy discussions about the transferability of credentials and access to institutions of higher education in other national contexts. Some were enticed by the new university in Sudan's Nuba Mountains, while others heard that daily attacks made attending classes impossible. Considering their options, the information youth accessed was inconsistent and often inaccurate. Though at times these conversations deviated from the original scope of our research questions, they were essential to the process of moving from research to action. As found in other YPAR 
collaborations (Nygreen, 2013), youth cultivated a sense of political agency not only through data collection and analysis, but also through critical dialogue and mutual support.

By far, the most widely shared question amongst participants and co-researchers centered on how to access higher education when one was not eligible for available scholarships. Once we articulated this question within the research group, it became a cornerstone of our shared work and a central question driving our action agenda. For example, Luke reflected that throughout his schooling, "People are saying work hard for the available scholarships. So I ask myself now, if I cannot get that scholarship, will I get further study or not?” This question surfaced in some form during nearly every group discussion, as well as private conversations when youth sought advice about how they might better leverage existing opportunities. Though they understood the fragility of hope in Kakuma and the need others felt to protect them through optimistic encouragement, there was also an emergent sense of betrayal. Those aiming to support youth often disarticulated encouragement from the realities of Kakuma's context, inspiring youth in the short-term but ultimately leaving them unprepared and ill-equipped to navigate challenges they would eventually encounter. Together, we wondered: if rejection and waiting were inevitable elements of postsecondary life, why had no one prepared them?

\section{Information Gaps and the Inequitable Distribution of Supports}

The lack of interactions grounded in concrete information contributed to what we began to refer to as information gaps. Information gaps encompassed everything from how and when to apply for available scholarships, how to learn about job opportunities and prepare for job interviews, the availability of trainings and other educational programming offered in the camp, eligibility requirements for educational and employment opportunities, and the transferability of credentials between borders and national educational systems. During one YPAR meeting, Nuor's personal invitation to apply for a new scholarship opportunity became illustrative of the ways that information was selectively, unsystematically, and often inequitably disseminated in the camp.

Nuor arrived at the meeting fifteen minutes late, wearing a gray skirt and oversized

polo. She unfolded a loose paper to show us why she was late. The organization that supported her secondary schooling is offering a new college scholarship, and they are encouraging "their students" to apply. She received a call this morning instructing her to stop by the office. Everyone in the group looked up, extending their arms until Nuor let go of the paper. She explained that it is for students whose exams scores fall between $\mathrm{C}$ and $\mathrm{D}+$, a range that excluded everyone in the room except 
her. Still, each of them gripped the edges of the paper for a long time before passing it. -Fieldnote, 1 April 2017

Theoretically, opportunities such as these were announced on camp notice boards, corkboards encased in glass doors, where refugees checked for job postings, updates on their asylum status, and meetings scheduled with UNHCR. But no one had seen this opportunity posted. As Ibrahim explained, “We cannot see every [notice board]. If you walk from Kakuma I to Kakuma II to Kakuma III... [to see all the boards], you will be very tired.” They understood that all opportunities could not be listed on every notice board, yet it was unrealistic to walk to each board and see the full range of opportunities. Additionally, the signs fluctuated so that a single person could not keep up to date.

An added impediment to distributing information, community members sometimes removed notices from the boards. This pattern surfaced in YPAR interviews, as several participants cited these removals as contributing to the challenges of finding work and other opportunities. Youth held mixed views on this phenomenon, with some believing that community members did not understand that the notice was a collective resource. However, most believed that the removals of postings were motivated by spite and fear of competition, or with the intention to circulate an opportunity narrowly within one's ethnic community. Rebecca complained, "They only want for themselves... They want that this opportunity is for their community." Aside from physical postings, informational exchanges in Kakuma depended on social networks and word of mouth, such as the call Nuor received. As Kariem explained, "the lack of information is a barrier." If young people could see how cumulative opportunities allowed for advancement toward educational credentials or employment opportunities, we reasoned, youth would approach their choices more strategically. Recognizing that young people's capacity to take advantage of existing opportunities depended on their awareness of the opportunities available, we designed a resource that aimed to close information gaps and instill a sense of "learned hopefulness" (Zimmerman, 1990).

\section{Disseminating Support: Creating a Resource by, for, and with Kakuma Youth}

Within the context of our YPAR collaboration, we designed a Facebook community page titled [name omitted for anonymous review]. The site situates learning as a lifelong endeavor, emphasizing a range of formal educational and training opportunities available to Kakuma youth after secondary school, as well as the possibility of "building a bridge" between secondary and postsecondary opportunities. The page encompasses multiple forms of non-material support, 
circling back to our initial themes: it offers information and advice about formal programming. It also manifests as a form of advocacy in its attempt to circulate information between, rather than solely within, identity groups. Additionally, the page aims to demystify misconceptions about accessing opportunities in the camp. For example, despite widespread beliefs that the "only way" to access higher education in exile was through scholarships, we articulated alternative pathways to postsecondary education. (See Figure 2.)

Building a bridge between secondary and postsecondary education is not without logistical and social challenges and ambiguities. Nuor regularly referred to this as "the long way," because it required almost a decade of additional schooling. Meanwhile, young people may be regarded as failures within their communities for not adhering to the linear path toward higher education, or they may encounter social stigma for their willingness to take on low-status work while building a bridge (AUTHOR 1). Nevertheless, building a bridge is one way to replace false hope with "material hope" (Duncan-Andrade 2009, p. 186), set within one's control, rather than subjecting one's future to the unpredictable nature of organizational priorities.

\section{[Insert figure 3 here].}

We set out to document the range of formal opportunities available to Kakuma youth, including technical and vocational courses, trainings, scholarships, and university loans. We also sought relevant contextual information such as deadlines, the duration and frequency of programming, eligibility requirements, and acceptance rates, so that site visitors could engage in comparative research across opportunities, set realistic goals, and intentionally prepare for application processes. Almost immediately as we envisioned the site's potential, doubts arose over the capacity of youth co-researchers to access this information. Kariem explained in clear terms, "We are not the kind of people that they [organizations] will give us the information." There were also concerns about how to navigate the power dynamic as youth beneficiaries engaging with the institutions that supported them. Would staff make time for their questions, or willingly share this information? Would the organization see these inquiries as affronts or critiques of the quality of their services? These questions and doubts lent support for the involvement of an adult facilitator in a primarily youth-led collaboration. (See Wong, Zimmerman, \& Parker, 2010 for further discussion of adult involvement in youth-led movements). To their surprise, every member of the youth research team managed to speak with an organizational representative. In some cases, coresearchers were praised for their interest in sharing information with the community in an innovative way, facilitating a broader reach than notice boards. The staff person Nuor spoke with 
closed their conversation with admiration for her effort: "What you are doing... is very good. You are helping your community... This is community work."

Co-researchers emphasized that their trust deepened with transparency and greater understanding of organizations' acceptance and hiring processes. Distinguishing between eligibility requirements and selection processes further mediated young people's perceptions of corruption. Kariem reflected that understanding the competitive nature of opportunities made it so that, "When you don't see your name there [on the list of selected candidates], you don't have any questions." We extensively considered the merits and drawbacks of understanding the selectivity of particular opportunities. Most members of the group agreed that knowing how competitive opportunities were - though jarring — would ultimately prove beneficial. One explained, "You have to prepare yourself... because it is not you alone seeking that particular course. You are very many... you have to also calibrate in your mind: maybe if I am eliminated, what should I do next?" Though not all organizations had access to the data we intended to document, all were forthcoming about their services, even when staff expressed concerns about publicizing particular information. For example, one staff member worried aloud that the success rate for applicants to a scholarship opportunity would demotivate young people, noting, "It is very low. Will it discourage them?"

Based on interviews and our efforts to document available resources, we identified five principal reasons why information was routinely withheld from, or otherwise rendered inaccessible to, Kakuma youth: information was (1) unsystematically distributed, (2) presumed to risk demoralization (upon learning how selective opportunities were), (3) in some cases assumed to be private or not accessible by refugees, who were supposed to accept whatever programming is offered when it is offered, (4) too unpredictable and dependent on the whims of donors and funding streams to be consistently useful, and (5) intentionally inequitably distributed (e.g., selectively hoarded within an identity group as a valuable resource). Further complicating matters, we too confronted these tensions as we decided whether, when, and how to circulate information on our site. We discussed at length how to present unfavorable information in ways that would minimize demoralization.

Youth researchers grappled with their own acceptance of the unsystematic nature of opportunities in the camp, and the ways that programmatic inconsistency at times liberated them from internalizing feelings of failure. Rather than take responsibility for not planning, they explained, they could place blame on "the system." As in other PAR collaborations (Cahill, 2007; Guishard, 2009), we wrestled with the borders between critical consciousness and hope. We aimed 
to empower Kakuma youth by explicitly orienting them to the opportunity structure, while not wanting to leave them despondent about how selective this structure was. In the terms used by Christens, Collura, and Tahir (2013), the goal of the site was to leave visitors both "critical and hopeful." But we consistently worried about shifting youth from a stance that was "uncritical but hopeful" to one that was "critical but alienated." That we too faced these challenges evidences the recursive nature of participatory action research, where the subject of inquiry is simultaneously a powerful force in one's own life experiences.

\section{Discussion}

Educational interventions for refugees tend to prioritize protection over long-term prevention and capacity-building, thus educating young people to cope within their present circumstances, "in isolation from their futures" (Dryden-Peterson, 2011, p. 85). This study emphasizes that expressions of support require contextualization and attention to the opportunity structure within the camp setting, a reality often absent from well-meaning, albeit abstract motivational discourse circulating Kakuma. That information about opportunity structuresaccounting for openings and constraints - can empower, rather than demoralize, youth goes against ingrained beliefs and practices in the camp. Individuals and institutions working in this context tend to operate with the assumption that unbound hope better serves refugees, while information that reveals the selectivity and embedded constraints of the educational opportunity structure will uniformly discourage and disempower. These findings point to shifts in educational practice that can better prepare young people for their future prospects while enduring protracted exile.

Information about organizational goals and selection processes enabled young people to be more planful in shaping their future pathways, enacting strategic agency, in that they anticipated long-term effects of their actions (Honwana, 2005, p. 49). By the end of our collaboration, several youth were making plans to build their own bridges towards higher education, while working and learning. Our emphasis on youth capacity-building should not detract from the urgent need to expand educational and livelihood opportunities for displaced youth. Nor do we deny the critical, motivational role of hope as central to shaping youth aspirations in the camp context. However, false hope has limited viability and hinders youth agency in favor of passively waiting for, rather than actively shaping, opportunities for learning and growth. As we demonstrate, eventually youth confront the constraints of the opportunity structure, finding themselves underprepared to navigate these challenges. One young person described the manufacturing of false hope in exile as "an empty suitcase...full of illusions" (UNHCR 2016, p. 21). False hope ignores systemic inequalities and the 
forces that contribute to forced exile, while maintaining "a false narrative of equal opportunity emptied of its historical and political contingencies" (Duncan-Andrade, 2009, p. 183). In contrast, critical, "material hope" stems from a "sense of control young people have when they are given... resources [to manage their lives]" (p. 186). Accounting for educational experiences amongst resettled refugees, Dryden-Peterson and Reddick (2017) similarly argue that shaping critical hope requires "addressing structural limitations directly" (p. 267).

Initially, the act of compiling data to document available opportunities, deadlines, and average numbers of applicants and candidates accepted into available programming provoked feelings of uncertainty about the inconsistency of organizational practices and how forthcoming staff would be about their selection processes, particularly with youth positioned as co-researchers in this investigation. Despite worries that refugee youth were not "the kind of people" who would be granted such information, co-researchers eventually came to see themselves as entitled to this information. Creating the online resource became an autonomous expression of the "right to research" (Appadurai, 2006) their community, as well as their capacity to assert themselves and engage with organizational actors whose programming shapes their lives and livelihood prospects. Continued involvement in the construction of the site persuaded youth that the information they sought was valuable and useful in planning their futures, and that they had the right and means to claim this information. Importantly, the research process and outcomes recast young people as rights-holders, rather than beneficiaries of services. These findings demonstrate the ways that YPAR positioned "the research itself... [as] part of the process of empowerment" (Morrell, 2008, p. 158), and thus constituted "an intervention in and of itself" (Langout \& Thomas, 2010, p. 61).

Young people's relative lack of understanding of the availability, nature, and distribution of postsecondary opportunities in the camp is a manifestation of their passive positioning in the face of services provided for them. Youth insights offer practical implications for how organizations working in camp settings can better interact with the communities they serve, particularly those that value local empowerment and capacity-building, as most claim to do. Challenging dependency discourses also points to the need to shift conceptions of agency within the camp, so that interacting with organizations, inquiring about existing programming, and demanding higher quality and more equitably distributed services are not seen as signs of ingratitude but rather as markers of engagement and investment in one's community. This study contributes to theories that youth empowerment is linked to broader contextual changes, with the potential to reshape norms underlying everyday interactions (Kohfeldt, Chhun, Grace, \& Langhout, 2011). However, the extent 
to which these effects might extend to other Kakuma youth and organizational practices will depend on how the collective resource is used and whether visitors to the site experience a similar role shift vis-à-vis camp service providers.

Greater transparency about selection practices also aimed to counter a culture of heightened competitiveness within the refugee community. Through the research process, young people recognized that information and opportunities were intentionally concentrated within identity groups, entrenching practices of nepotism, tribalism, and other forms of identity-based discrimination. Tensions between identity groups became particularly pronounced after schooling ended, as there were fewer spaces for diverse groups to interact, and young people actively competed for limited opportunities. Our site intended to create a sense of mutuality through an expanded social network of Kakuma youth, encompassing all young people regardless of their identity or status. Further research is needed to investigate the efficacy of youth-driven efforts to foster inclusion, and the extent to which more expansive identities can combat ethnic and national discrimination.

The interface between hope, despondency, and critical awareness constitutes an important dimension of camp life and global developmental interventions aimed at youth empowerment (Abdi, 2005; Dryden-Peterson, 2011). These tensions also intersect with YPAR approaches, in that supporting young people's critical consciousness of multiple and systemic inequities and injustices that impact their lives risks leaving youth feeling hopeless, particularly if they are not given the chance to respond to, or act on, their experiences with marginalization (Cahill, 2007; Ginwright, Cammarota, \& Noguera, 2006; Guishard, 2009). Conceptions of the refugee camp as a temporary space of exile further impeded the sustainability expected of YPAR and community mobilizations. Beyond their capacity to act, young people did not feel a strong obligation to contribute to the common good within Kakuma, desiring to move on from "this waiting place," rather than improve it. Despite our awareness that these tensions motivated some of the routine withholding of information in Kakuma, they also factored into our own research interactions. On some occasions, we relied on and even amplified dominant, abstract motivational discourses, worried that too much realism would deepen youth cynicism and despair. Developing the social media site gave youth coresearchers a chance to respond to these challenges, calling for youth aspirations rooted in "learned hopefulness" (Zimmerman, 1990). Their focused, and at times hesitant, attempts to balance obligatory optimism with pragmatic realism illustrate the ways that critical awareness 
fundamentally shapes youth subjectivity, with important consequences for the agency young people bring to bear on their futures (Cole \& Durham, 2008).

\section{Conclusion}

The YPAR collaboration challenged long-held beliefs that unbound hope is the most vital form of non-material support in Kakuma Refugee Camp. Young people aided by - and often constrained by - the opportunity structures in Kakuma and the global power hierarchies in which these structures are embedded, require more than inspirational messages aimed at coping and hoping. Young people are entitled to the contextual information and skills necessary to realize their future aspirations, allowing for informed decision-making and the capacity to participate in dialogue and debates that concern their lives and livelihoods. Without a clear sense of how to access, shape, or leverage existing opportunities, young people are left with aspiration as their only recourse to agency. However, "without systematic tools for gaining relevant new knowledge, aspiration degenerates into fantasy or despair" (Appadurai, 2006). In many cases, decontextualized hope left young people with unrealistic expectations and little preparation for the challenges ahead. Closing information gaps is key to youth empowerment, in that it allows them to understand and navigate the material conditions of their lives.

The YPAR collaboration employed and affirmed refugees' capacity to self-advocate, countering beliefs, from within and outside Kakuma, that refugees lack the will and agency to take

control of their lives. Refugees lack legal citizenship status but nonetheless have rights to uphold. Willfully ignoring the constraints on realizing these rights in the camp context - such as the inconsistent, inequitable, and unsystematic nature of accessing information — while boosting abstract hope does little to support youth capacity to aspire, research, and plan their futures in exile. It is important to grant young people a realistic sense of opportunities available to them as they set goals, clear information about how to access those opportunities, and the capacity to plan the steps necessary to achieve those goals, while providing support along the way.

\section{References}

Abdi, A.M. (2005). In limbo: dependency, insecurity and identity among Somali refugees in Dadaab camps. Refuge, 22(2), 6-14.

Appadurai, A. (2004). The capacity to aspire: Culture and the terms of recognition. In V. Rao \& M. Walton (Eds.), Culture and Public Action (pp. 59-84). Stanford, CA: Stasnford University Press.

This article is protected by copyright. All rights reserved 
Appadurai, A. (2006). The right to research. Globalisation, Societies \& Education, 4(2), 167-177.

Cahill, C. (2007). Repositioning ethical commitments: Participatory Action Research as a relational praxis of social change. ACME: An International E-Journal for Critical Geographies, 6(3), 360-373.

Cammarota, J., \& Fine, M. (Eds.). (2008). Revolutionizing Education: Youth Participatory Action Research in Motion. New York: Routledge.

Caraballo, L., Lozenski, B. D., \& Lyiscott, J. J. (2017). PAR and critical epistemologies: Rethinking education research. Review of Research in Education, 41, 311-336.

Carballo, M., Smajkic, A., Zeric, D., Dzidowska, M., Gebre-Medhin, J., \& Halem, J. V. (2004). Mental health and coping in a war situation: The case of Bosnia and Herzegovina. Journal of Biosoc Science, 36, 463-477.

Case, A. D., Todd, N. R., \& Kral, M. J. (2014). Ethnography in Community Psychology: Promises and Tensions. American Journal of Community Psychology, 54, 60-71.

Christens, B. D., Collura, J. J., \& Tahir, F. (2013). Critical Hopefulness: A Person-Centered Analysis of the Intersection of Cognitive and Emotional Empowerment. American Journal of Community Psychology, 52, 170-184. doi:10.1007/s10464-013-9586-2

Couch, J., \& Francis, S. (2006). Participation for All? Searching for Marginalized Voices: The Case for Including Refugee Young People. Children, Youth and Environments, 16(2), 272-290.

Chataway, C. J. (1997). An examination of the constraints on mutual inquiry in a participatory action research project. Journal of Social Issues, 53(4), 747-765.

Checkoway, B., \& Richards-Schuster, K. (2004). Youth Participation in Evaluation and Research as a Way of Lifting New Voices. Children, Youth and Environments, 14(2), 85-98.

Cole, J., \& Durham, D. (2008). Introduction: Globalization and the temporalities of children and youth. In J. Cole \& D. Durham (Eds.), Figuring the future: Globalization and the temporalities of children and youth. Santa Fe, NM: School for Advanced Research Press.

Crisp, J. (2004). The local integration and local settlement of refugees: A conceptual and historical analysis. Geneva: UNHCR.

Davies, L. (2004). Building a civic culture post-conflict. London Review of Education, 2(3), 229244.

Dryden-Peterson, S. (2011). Refugee children aspiring toward the future: Linking education and livelihoods. In K. Mundy \& S. Dryden-Peterson (Eds.), Educating children in conflict zones: 
Research, policy, and practice for systemic change (pp. 85-99). New York: Teachers College Press.

Dryden-Peterson, S. (2016). Refugee education: The crossroads of globalization. Educational

Researcher, 45, 473-482.

Dryden-Peterson, S., \& Reddick, C. (2017). "When I am a President of Guinea": Resettled refugees traversing education in search of a future. European Education, 49(4), 253-275.

Duncan-Andrade, J. M. R. (2009). Note to educators: Hope required when growing roses in concrete. Harvard Educational Review, 79(2), 181-194.

Fine, M., \& Burns, A. (2003). Class notes: Towards a critical psychology of class and schooling. Journal of Social Issues, 59(4), 841-860.

Ginwright, S.A., Cammarota, J., \& Noguera, P.A. (Eds.). 2006. Beyond Resistance: Youth Activism and Community Change: New Democratic Possibilities for Policy and Practice for America's Youth. New York, NY: Routlege.

Gladwell, C., Hollow, D., Robinson, A., Norman, B., Bowerman, E., Mitchell, J., Floremont, F., Hutchinson, P. (2016). Higher education for refugees in low resource environments: Research study. United Kingdom: Jigsaw.

Guishard, M. (2009). The false paths, the endless labors, the turns now this way and now that: Participatory Action Research, mutual vulnerability, and the politics of inquiry. The Urban Review, 41(1), 85-105.

Harry, B., Sturges, K.M., \& Klingner, J.K. (2005). Mapping the process: An exemplar of process and challenge in grounded theory analysis. Educational Researcher, 34(2), 3-13.

Harvey, P., \& Lind, J. (2005). Dependency and humanitarian relief: A critical analysis. London, UK: Humanitarian Policy Group, Overseas Development Institute.

Honwana, A. (2005). Innocent and guilty: Child-soldiers as interstitial and tactical agents. In A. Honwana \& F. De Boeck (Eds.), Makers and breakers: Children and youth in postcolonial Africa (pp. 31-52). Trenton, NJ: Africa World Press.

Jacquez, F., Vaughn, L. M., \& Wagner, E. (2013). Youth as Partners, Participants or Passive Recipients: A Review of Children and Adolescents in Community-Based Participatory Research (CBPR). American Journal of Community Psychology, 51, 176-189.

Kidd, S., Davidson, L., Frederick, T., \& Kral, M. J. (2017). Reflecting on Participatory, ActionOriented Research Methods in Community Psychology: Progress, Problems, and Paths Forward. American Journal of Community Psychology, 0, 1-12. doi:10.1002/ajcp.12214 
Kirshner, B. (2010). Productive tensions in youth participatory action research. Yearbook of the National Society for the Study of Education, 109(1), 238-251.

Langhout, R. D., Collins, C., \& Ellison, E. R. (2014). Examining Relational Empowerment for Elementary School Students in a YPAR Program. American Journal of Community Psychology, 53, 369-381. doi:10.1007/s 10464-013-9617-z

Langhout, R. D., \& Thomas, E. (2010). Imagining Participatory Action Research in Collaboration with Children: an Introduction. American Journal of Community Psychology, 46, 60-66. doi:10.1007/s10464-010-9321-1

Mosselson, J., Morshed, M. M., \& Changamire, N. (2017). Education and Wellbeing for Refugee Youth. Peace Review, 29(1), 15-23. doi:10.1080/10402659.2017.1272281

Nordstrom, C. (2004). Shadows of war: Violence, power, and international profiteering in the twenty-first century. Berkeley: University of California Press.

Nygreen, K. (2009). Critical dilemmas in PAR: Towards a new theory of engaged research for social change. Social Justice, 36(4), 14-35.

Ozer, E. J., Ritterman, M. L., \& Wanis, M. G. (2010). E. Participatory Action Research (PAR) in Middle School: Opportunities, Constraints, and Key Processes. American Journal of Community Psychology, 46, 152-166. doi:10.1007/s10464-010-9335-8

Prilleltensky, I. (2010). Child Wellness and Social Inclusion: Values for Action. American Journal of Community Psychology, 46, 238-249. doi:10.1007/s10464-010-9318-9

Schensul, J.J., Berg, M.,\& Sydlo, S. (2004).Core elements of participatory action research for educational empowerment and risk prevention with urban youth. Practicing Anthropology, 26(2), 5-8.

Smagorinsky, Peter. 2008. The Method Section as Conceptual Epicenter in Constructing Social Science Research Reports. Written Communication, 25(3), 389-411.

Quinn, R. (2010). Attacks on higher education communities: A holistic, human rights approach to protection. In UNESCO (Ed.), Protecting education from attack: A state-of-the-art review (pp. 99-110). Paris, France: UNESCO.

Rodriguez, L. F., \& Brown, T. M. (2009). From voice to agency: Guiding principles for participatory action research with youth. New Directions for Youth Development, 123, 1934.

Seidman, I. (2013). Interviewing as qualitative research: A guide for researchers in education and the social sciences. New York: Teachers College Press.

This article is protected by copyright. All rights reserved 
Shaw, R., Waldorf, L., \& Hazan, P. (Eds.). (2010). Localizing transitional justice: Interventions and priorities after mass violence. Stanford, CA: Stanford University Press.

Stambach, A., \& Hall, K. D. (Eds.). (2017). Anthropological perspectives on student futures: youth and the politics of possibility. New York: Palgrave Macmillan.

Tuck, E., Allen, J., Bacha, M., Morales, A., Quinter, S., Thompson, J. \& Tuck, M. (2008). PAR praxes for now and future change: The collective of researchers on educational disappointment and desire. In J.Cammarota \& M. Fine (Eds.), Revolutionizing Education: Youth Participatory Action Research in Motion, (pp. 49-83). New York, NY: Routledge.

UNHCR. (2015). UNHCR Global trends: Forced displacement in 2014. Geneva: UNHCR.

UNHCR. (2016a). Missing out: Refugee education in crisis. Geneva: UNHCR.

UNHCR. (2016b). "We believe in youth": Global refugee youth consultations, Final report. Geneva: UNHCR.

Winthrop, R., \& Kirk, J. (2008). Learning for a Bright Future: Schooling, Armed Conflict, and Children's Well-Being. Comparative Education Review, 52(4), 639-661.

Wong, N. T., Zimmerman, M. A., \& Parker, E. A. (2010). A Typology of Youth Participation and Empowerment for Child and Adolescent Health Promotion. American Journal of Community Psychology, 46, 100-114. doi:10.1007/s10464-010-9330-0

Zimmerman, M. A. (1990). Toward a theory of learned hopefulness: A structural model analysis of participation and empowerment. Journal of Research in Personality, 24, 71-86. doi:10.1016/0092-6566(90)90007-S

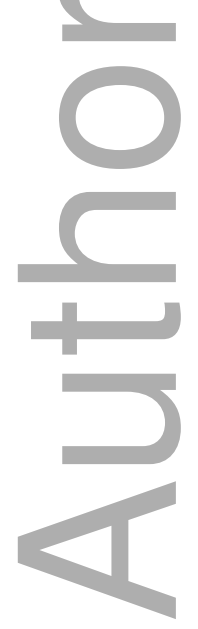

This article is protected by copyright. All rights reserved 
Table 1: Participant demographics (selected by youth co-researchers)

\begin{tabular}{|l|l|}
\hline Demographic variable & Percentage of participants \\
\hline Gender & Male- 78\% F- 22\% \\
\hline Age Range & $16-36$ years \\
\hline Country of origin & $3 \%$ \\
\hline Burundi & $6 \%$ \\
\hline Congo & $13 \%$ \\
\hline Kenya & $9 \%$ \\
\hline Somali & $25 \%$ \\
\hline South Sudan & $41 \%$ \\
\hline Sudan & $3 \%$ \\
\hline Uganda & $6 \%$ \\
\hline Current work or education status & $38 \%$ \\
\hline Primary school student & $28 \%$ \\
\hline Secondary school student & $9 \%$ \\
\hline Unemployed Form 4 leaver & $13 \%$ \\
\hline Employed Form 4 leaver & $6 \%$ \\
\hline University student & \\
\hline University graduate & \\
\hline
\end{tabular}

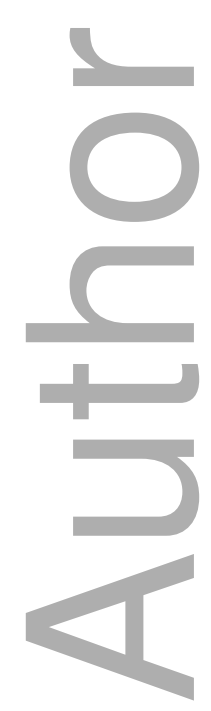


Figure 1: Transition crunch between primary and secondary school enrollment

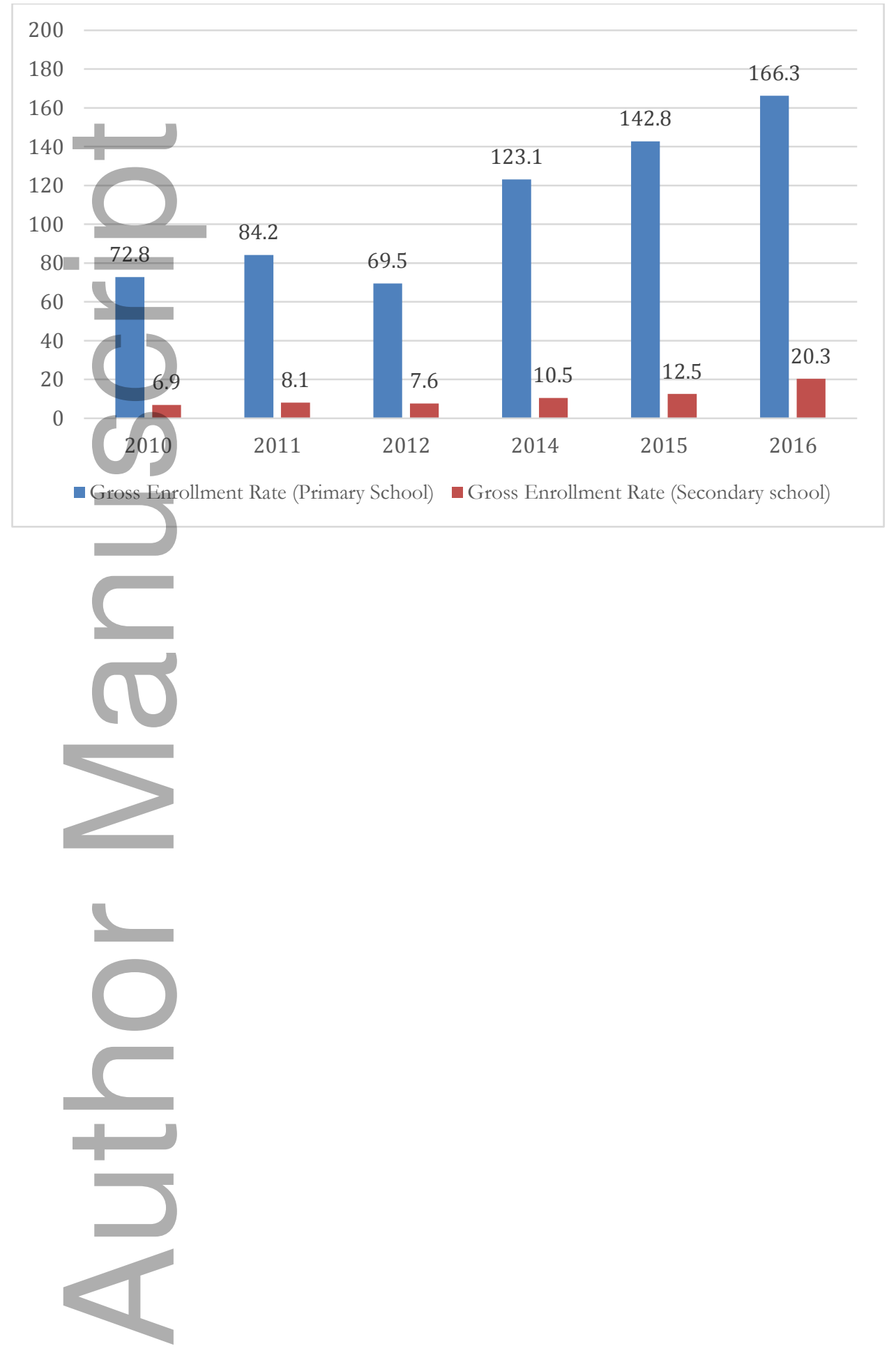


Figure 1: Transition crunch between primary and secondary school enrollment

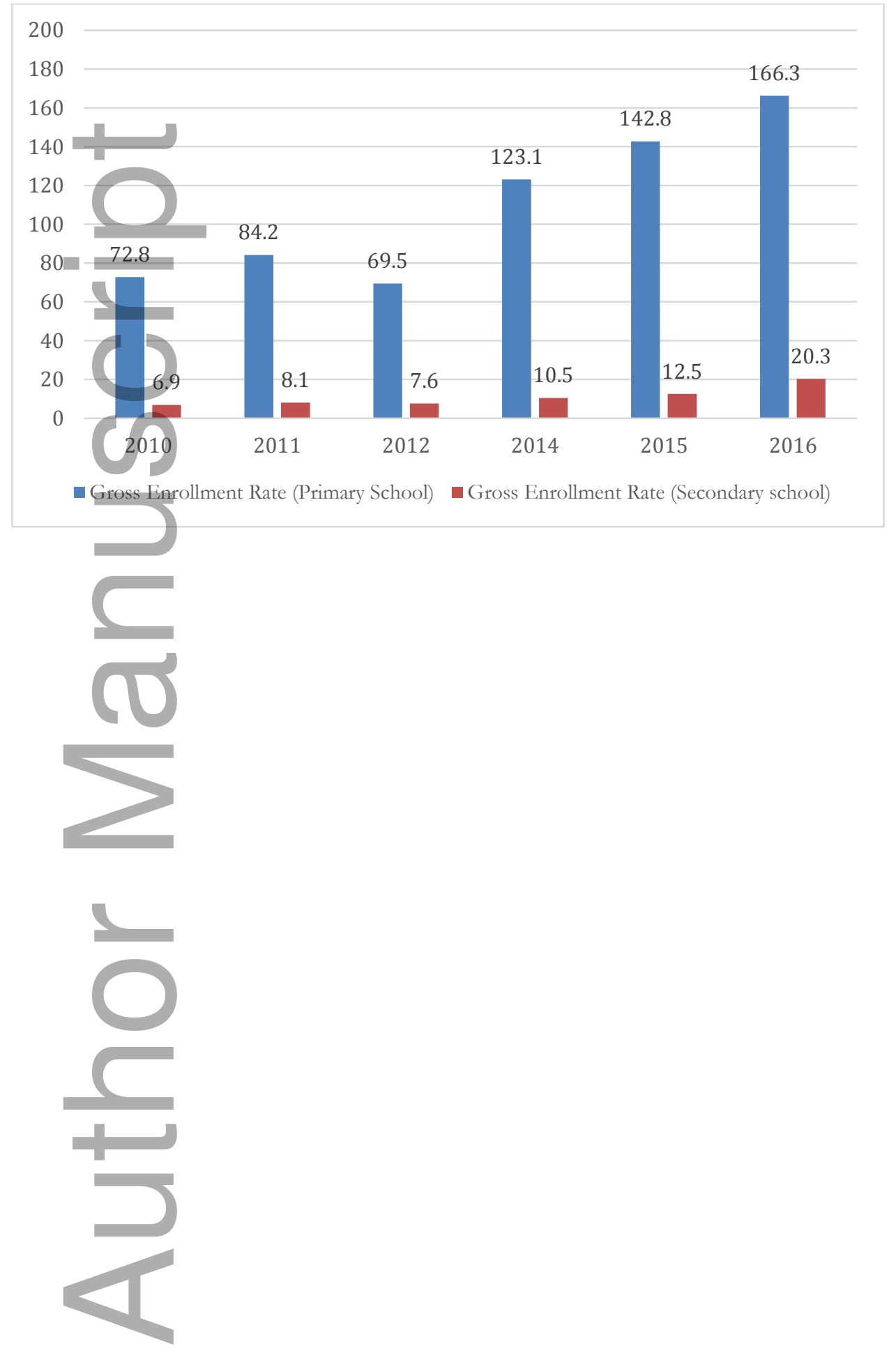


Figure 2: Building a bridge from basic to higher education

\section{Linear trajectory}
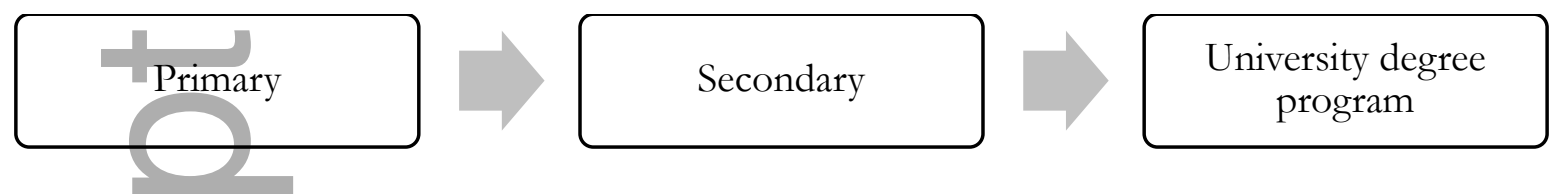

\section{Building a bridge}
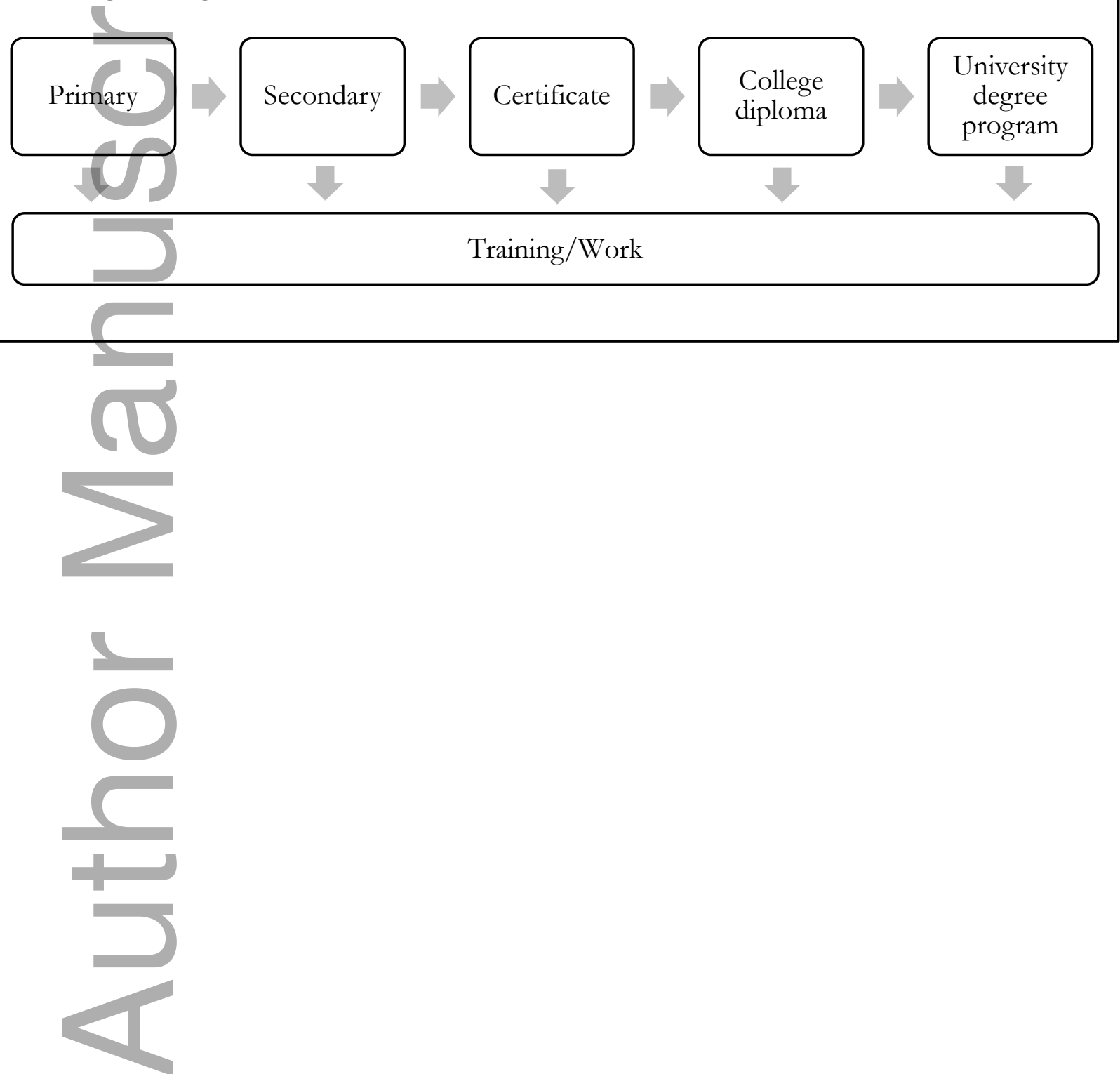
Figure 2: Building a bridge from basic to higher education

\section{Linear trajectory}
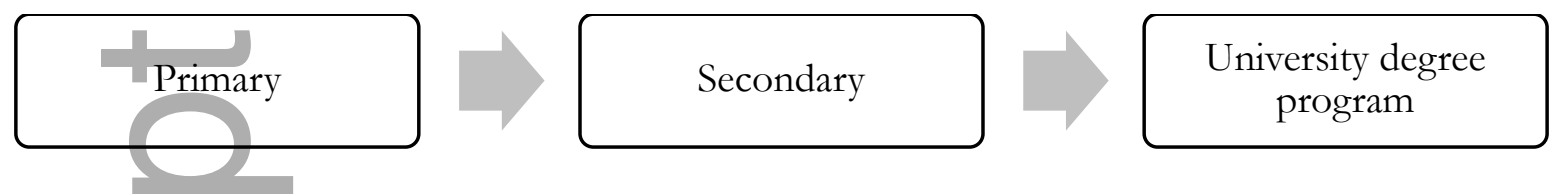

\section{Building a bridge}
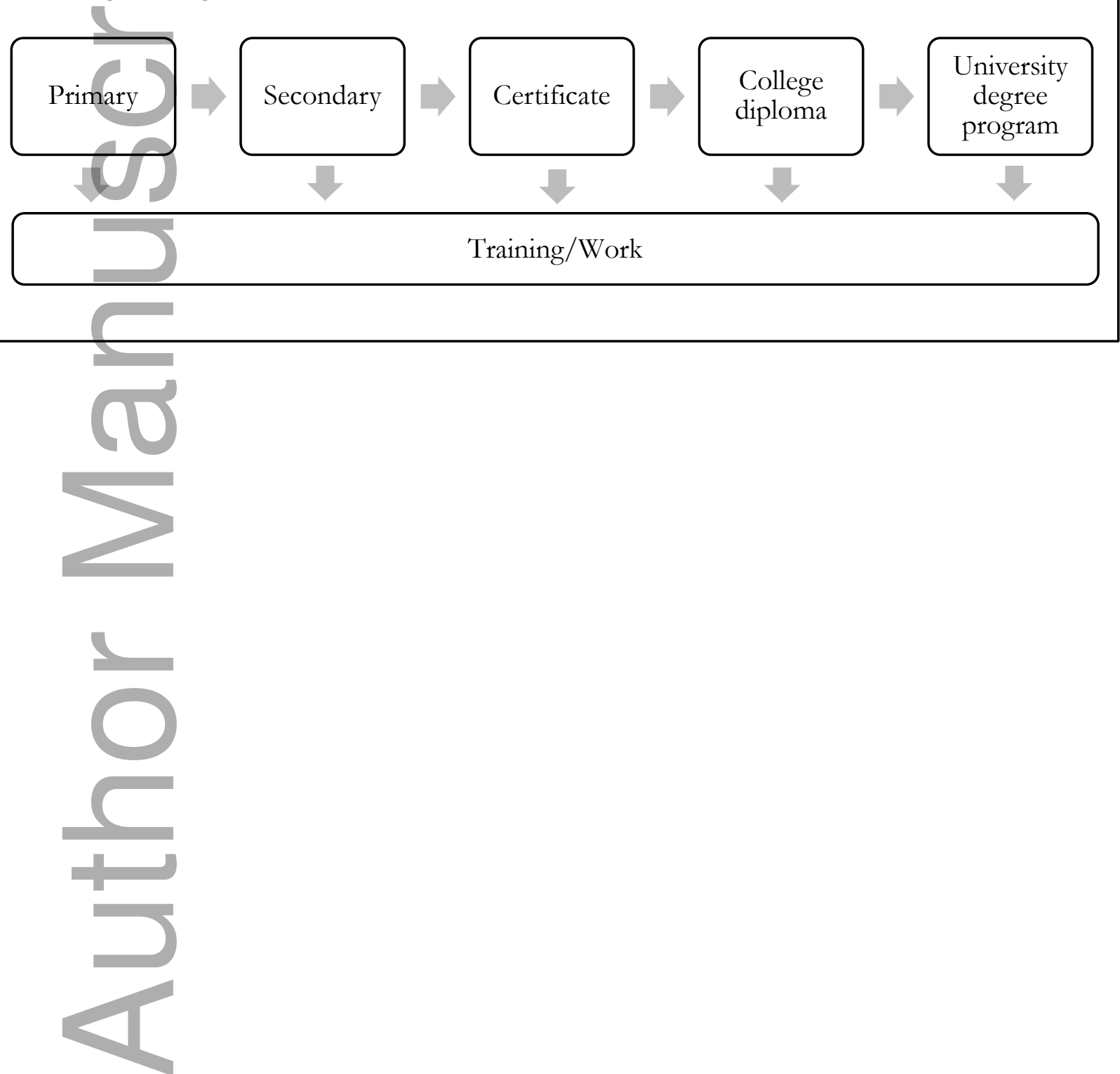